of absolute continuity of $Q$ with respect to $P$ on $Q$; the conclusions may be strengthened by asserting $Q$ mixing of these sequences with the limiting distribution function $F(y)$, instead of only the convergence of the distribution functions of the averages to $F(y)$.

\title{
BIBLIOGRAPHY
}

1. J. L. Doob, Stochastic processes, Wiley, New York, 1953.

2. V. A. Rokhlin, New progress in the theory of transformations with invariant measure, Uspehi Mat. Nauk (1960), English translation published by the London Math. Soc.

3. A. Rényi, On mixing sequences of sets, Acta Math. Acad. Sci. Hungar. 9 (1958), 215-228.

4. E. S. Andersen and B. Jessen, Some limit theorems on set-functions, Danske Vid. Selsk. Mat.-Fys. Medd. 25 (1948).

5. J. H. Abbott and R. J. Blum, On a theorem of Rényi concerning mixing sequences of sets, Ann. Math. Statist. 32 (1961), 257-260.

6. A. Rényi and P. Révész, On mixing sequences of random variables, Acta Math. Acad. Sci. Hungar. 9 (1958), 389-393.

University of Wisconsin, Milwaukee

\section{THE EQUATION $\left(\partial^{2} / \partial x^{2}+\partial^{2} / \partial y^{2}+\left(x^{2}+y^{2}\right)(\partial / \partial t)\right)^{2} u+\partial^{2} u / \partial t^{2}=f$, WITH REAL COEFFICIENTS, IS "WITHOUT SOLUTIONS"}

\author{
BY FRANÇOIS TREVES ${ }^{1}$ \\ Communicated by Lipman Bers, February 20, 1962
}

Indeed, the equation can be written $P P^{*}\left(P P^{*}\right)^{*} u=f$, where $P$ is Lewy's operator $\partial / \partial \bar{z}+i z(\partial / \partial t),{ }^{2} z=x+i y$, and the star operation replaces the coefficients of a differential operator by their complex conjugates. Hörmander has shown ${ }^{3}$ that, whatever be the open set $\Omega$, there is a function $f \in C_{0}^{\infty}(\Omega)$ such that the equation $P v=f$ does not have any distribution solution $v \in D^{\prime}(\Omega)$.

YESHIVA UNIVERSITY

${ }^{1}$ Sloan fellow. Yeshiva University, New York City.

${ }^{2} \mathrm{H}$. Lewy, An example of a smooth linear partial differential equation without solution, Ann. of Math. (2) 66 (1957), 155.

${ }^{3}$ L. Hörmander, Differential equations without solutions, Math. Ann. 140 (1960), 169. 